\title{
Cenas discursivas da pandemia de Covid-19: o discurso sobre o isolamento social na imprensa
}

\section{Covid-19 pandemic discourse scenes: the discourse of social isolation in the press}

\section{Escenas del discurso de la pandemia de Covid-19: el discurso del aislamiento social en la prensa}

Wedencley Alves ${ }^{1, a}$

wedencley@gmail.com | https://orcid.org/oooo-0002-3411-727X

Denise Nacif Pimenta ${ }^{2, b}$

denise.pimenta@fiocruz.br | https://orcid.org/o0oo-0003-3248-9472

Michele Nacif Antunes ${ }^{3,0}$

michelenantunes@gmail.com | https://orcid.org/0000-0001-8500-8930

${ }^{1}$ Universidade Federal de Juiz de Fora, Faculdade de Comunicação. Juiz de Fora, MG, Brasil.

2 Fundação Oswaldo Cruz, Centro de Pesquisas René Rachou. Belo Horizonte, MG, Brasil.

3 Universidade Federal do Espírito Santo, Programa de Pós-Graduação em Saúde Coletiva. Vitória, ES, Brasil.

a Doutorado em Linguística pela Universidade Estadual de Campinas.

' Doutorado em Ciências da Saúde pela Fundação Oswaldo Cruz.

c Doutorado em Saúde Coletiva pela Universidade Federal do Espírito Santo.

\section{RESUMO}

O presente artigo tem como objetivo analisar discursos do/no jornal O Globo, um veículo de referência no jornalismo brasileiro, sobre a estratégia de isolamento social como forma de contenção da pandemia de Covid-19. Para isso, tomou como base de observação e análise notícias e reportagens publicadas pelo jornal durante as duas primeiras semanas de medidas (do dia 16 ao dia 26 do mês de março de 2020). O estudo partiu da Análise de Discurso (Pêcheux/Orlandi) para compreender se houve deslocamentos de sentido em relação às medidas e aos embates discursivos que tiveram lugar entre autoridades políticas, de saúde e a própria população. $\mathrm{O}$ artigo conclui que mais do que produzir sentido sobre a cena discursiva que se instaurou durante esse período, o próprio jornal se fez ator nessa cena, participando de intrigas discursivas que nela tiveram lugar.

Palavras-chave: Mídia impressa; Jornal; Discurso; Covid-19; Pandemia. 


\section{ABSTRACT}

This article aims to analyze discourses by/in the newspaper O Globo, a reference vehicle in Brazilian journalism, about the strategy of social isolation as a way of containing the Covid-19 pandemic. For this purpose, it took as a base of observation and analysis news and reports published by the newspaper during the first two weeks of measures (from March 16 to 26). The study started from Discourse Analysis (Pêcheux/ Orlandi) to understand if there have been displacements of meanings in relation to measures and the discursive clashes that took place between political, health authorities and the population itself. The article concludes that more than producing meaning about the discursive scene that was established during that period, the newspaper itself became an actor in that scene, participating in the discursive intrigues that took place on it.

Keywords: Press; Newspaper; Discourse; Covid-19; Pandemic.

\section{RESUMEN}

Este artículo tiene como objetivo analizar los discursos del diario O Globo, vehículo de referencia en el periodismo brasileño, sobre la estrategia de aislamiento social como forma de contener la pandemia Covid-19. Para ello, tomó como base de observación y análisis las noticias e informes publicados por el diario durante las primeras dos semanas de medidas (del 16 al 26 de marzo). El estudio partió del Análisis del Discurso (Pêcheux/Orlandi) para entender si hubo algún desplazamiento de sentidos con relación a las medidas y los enfrentamientos discursivos que se produjeron entre las autoridades políticas, sanitarias y la propia población. El artículo concluye que más que producir significado sobre la escena discursiva que se instauró durante ese período, el propio diario se convirtió en actor de esa escena, participando de las intrigas discursivas que se desarrollaban en ella.

Palabras clave: Prensa; Periódico, Discurso; Covid-19; Pandemia.

Este artigo compõe o dossiê Comunicação, Saúde e Crises Globais: parte 2.

Contribuição dos autores:

Concepção e desenho do estudo: Wedencley Alves.

Aquisição, análise ou interpretação dos dados: Wedencley Alves, Denise Nacif Pimenta e Michele Nacif Antunes.

Redação do manuscrito: Wedencley Alves, Denise Nacif Pimenta e Michele Nacif Antunes.

Revisão crítica do conteúdo intelectual: Michele Nacif Antunes e Denise Nacif Pimenta.

Declaração de conflito de interesses: não há.

Fontes de financiamento: não houve.

Considerações éticas: não há.

Agradecimentos/Contribuições adicionais: não há.

Histórico do artigo: submetido: 8 set. 2020 | aceito: 21 dez. 2020 | publicado: 22 mar. 2021.

Apresentação anterior: não há.

Licença CC BY-NC atribuição não comercial. Com essa licença é permitido acessar, baixar (download), copiar, imprimir, compartilhar, reutilizar e distribuir os artigos, desde que para uso não comercial e com a citação da fonte, conferindo os devidos créditos de autoria e menção à Reciis. Nesses casos, nenhuma permissão é necessária por parte dos autores ou dos editores. 


\section{INTRODUÇÃO}

Um cenário de crise, seja qual for, é também um cenário de disputas de sentido. As crises apontam, embora nem sempre resultem, para a desestabilização de discursos estabelecidos em relações múltiplas de forças sociais e históricas. Nessas crises, sejam elas políticas, econômicas ou institucionais, costumam-se constituir cenas discursivas nas quais, analiticamente, pode-se observar embates entre atores sociais e institucionais posicionados em formações discursivas concorrentes, que tentam de alguma forma garantir seus gestos de interpretação como dominantes na luta pela "fabricação do consenso" (ORLANDI, 2010, p. 6).

A questão que move esse estudo é: em meio ao acontecimento histórico da pandemia de Covid-19 em 2020, uma crise sanitária de dimensões extraordinárias, pode-se observar algum deslizamento de sentido, ou mesmo acontecimentos discursivos na imprensa nacional? É possível verificar ressignificações sobre o sentido de isolamento social ao longo do período analisado?

A fim de responder a essa questão, utilizamos como corpus os textos do Jornal O Globo, um dos mais tradicionais veículos brasileiros da chamada grande imprensa, com 95 anos de existência, o segundo maior jornal de referência em circulação no País, segundo dados do Instituto de Verificação de Circulação (SACCHITIELLO, 2020).

Para a análise, partimos de conceitos já estabelecidos no quadro teórico da Análise de Discurso e propusemos outros dispositivos conceituais, como cena discursiva e intriga, atos enunciativos e formas discursivas, que nos auxiliarão a ser mais precisos na localização de variáveis enunciativas do processo discursivo em análise. Nosso ponto de ancoragem no texto foi a locução nominal 'isolamento social', com buscas no acervo digital do próprio veículo. O período analisado foram as duas primeiras semanas de cobertura sobre o tema: de 15 de março (quando entraram em vigor as medidas anunciadas pelos governadores no dia anterior) a 26 de março de 2020 (ponto em que o jornal entra diretamente em embate com o governo federal, tendência que se segue nos dias seguintes da mesma semana). Recorremos também à locução nominal 'distanciamento social' para efeito de comparação em relação aos usos anteriores ao período analisado, apenas de forma introdutória.

O estudo teve como objetivo analisar os discursos do/no jornal O Globo sobre a política de isolamento social defendida pela Organização Mundial da Saúde e diversas autoridades sanitárias e científicas durante a crise provocada pela pandemia de Covid-19. Sua justificativa está na importância de compreender a atuação da imprensa nesse momento, visto que na mídia podem ser observados muitos dos sentidos postos em movimento durante a crise.

\section{UMA QUESTÃO DISCURSIVA}

Acontecimentos históricos e discursivos não estão em relação necessária de motivação e efeito, o que resulta na compreensão a seguir: crises políticas, econômicas e/ou institucionais não resultam, forçosamente, em 'crises discursivas', ou seja, ocorrência de reviravoltas no campo dos sentidosi. Portanto, podem-se esperar embates entre atores, em suas posições, mas não é certo que tenhamos reposicionamentos desses atores ou mudanças efetivas no quadro de formações discursivas (doravante FD), conceito basilar na Análise de Discurso, pois distingue uma matriz de sentidos a partir da qual o sujeito produz gestos de interpretação.

i Para uma discussão aprofundada sobre a relação entre história e acontecimento discursivo, recomendamos Guilhaumou (2007). 
No processo de análise, as FDs são os traços de regularidade, de paráfrase, a serem identificados em textos e outras materialidadesii.

De certa forma, graças à heterogeneidade discursiva, sempre teremos FDs em contraposição, quando sabemos que a simples presença de uma FD no texto consiste no silenciamento de outra, sua concorrente. No entanto, no texto jornalístico, os embates podem ser 'encenados', mostrados ou não. Quando encenados, temos um jogo de antagonismos que nós denominaremos 'intriga' ou 'trama'. Essa intriga pode ser simulada, no caso de embate de atores de mesma formação discursiva; ou efetiva, quando realmente temos evidenciado um embate de FDs. É nesse caso que propomos falar de cena discursiva ${ }^{\text {iii. }}$.

Em um cenário de crise, no entanto, é improvável que algum antagonismo não se estabeleça, porque as forças históricas, políticas, mesmo que antes apenas subsumidas, emergem pelo próprio efeito da tensão desencadeadora da crise. Ademais, não raramente, o veículo sai do seu lugar de relator ou narrador e literalmente entra em cena assumindo para o leitor certo lugar na intriga.

Por vezes, é justamente a emergência daquelas forças ou seu deslocamento que vem provocar a crise. A compreensão do lugar da imprensa na composição de cenas discursivas (e suas intrigas) é de real importância para a compreensão de como discursos sobre saúde pública são potencializados ou atenuados, vocalizados ou silenciados, envolvidos em disputas pelo poder de nomeação e de arquivo. Além disso, auxilia a entender como, de alguma forma, dada a centralidade da mídia para a percepção de mundo dos indivíduos, muito desse jogo é traçado nos jornais, rádios, TVs e redes, que vai resultar algum efeito de realidade para boa parte dos indivíduos. Portanto, trata-se de uma questão que não diz respeito somente a pesquisadores de comunicação, mas também a pesquisadores de saúde e formuladores de políticas públicas.

O caso em estudo tem uma particularidade que não pode ser igualada às crises políticas, econômicas, institucionais clássicas, nem pode ser aproximada a outras formas de crise sanitária (ambientais, flagelos por fome, desastres socioambientais). Um surto, um evento endêmico e mesmo uma epidemia não podem ser contidos dentro da regularidade das instituições, dos discursos mais ou menos tomados como garantidores de uma ordem de sentidos já estabilizada. Uma pandemia, no entanto, acaba por fazer emergir certas tensões amainadas historicamente. A pandemia de Covid-19 tem particularidades dentro dessas particularidades.

A pandemia de 2020 se assemelha à epidemia de Sars e Mers pelos agentes causadores e pelo grau de letalidade, mas estas foram muito regionalizadas (MARTIN, 2020), ainda mais do que aquela de ebola ocorrida em África (CDC, 2019). Pela extensão, poderia se comparar à H1N1, mas em relação a esse evento de influenza, a Covid-19 se mostrou muito mais letal (WHO, 2020).

Outra comparação poderia ser feita com aquela dos anos 1980, a de HIV, que se tornou endêmica na maioria dos países do mundo e limou, até agora, a vida de cerca de 30 milhões de pessoas. As diferenças: as formas de contágio e o tempo da doença são absolutamente diferentes da Covid-19. Isso resulta que basicamente 'só os doentes' sofreriam diretamente com a doença. Embora menos letal que o HIV, o coronavírus trouxe profundos abalos sanitários, médicos, sociais, políticos e econômicos e na estrutura de emprego e renda das famílias. Ou seja, embora seu agente infeccioso apresente menor letalidade que aqueles das doenças supracitadas, foi a pandemia que mais impactou a Humanidade desde a gripe espanhola.

Como o HIV-AIDS, esta crise sanitária transcendeu as questões médicas propriamente vistas. Além das mortes, do sofrimento, da destruição emocional de famílias inteiras, sobreviventes, ela também trouxe uma enorme incerteza no mundo das ciências biomédicas. Diz-se que o HIV liquidou o triunfalismo do discurso

ii Recorremos a Orlandi, para a definição clássica de FD: “A formação discursiva se define como aquilo que numa formação ideológica dada - ou seja, a partir de uma posição dada em uma conjuntura sócio-histórica dada - determina o que pode e deve ser dito" (2009, p. 43).

iii Sobre a intriga, trata-se de uma apropriação do conceito retomado por Paul Ricoeur (2011) da tradição aristotélica, e sua adequação ao quadro teórico da Análise do Discurso. 
médico nos anos 1980, a ideia de que todas as doenças de certa forma poderiam ser erradicadas ou ao menos controladas com o avanço da medicina (MOULIN, 2008), e a Covid-19 aprofundou tais incertezas ${ }^{\text {iv }}$.

É neste quadro que, desarmados de opções farmacológicas, medidas de contenção de formas de contágio foram adotadas por diversos países do mundo sob orientação da OMS e de instituições internacionais de pesquisa. Uma delas, a do isolamento social, objeto desse escrito, embora amplamente aceito em vários países, não foi uma medida de aprovação unânime e, mesmo quando implementada, acabou por ter adesão em tempos diferentes.

Podemos reunir os países em quatro grupos segundo suas reações às medidas recomendadas de isolamento: aqueles que aderiram imediatamente (China, Coréia do Sul, Cingapura, Portugal, Argentina etc.); aqueles que aderiram tardiamente (Itália, França, Inglaterra, Alemanha etc.); aqueles que se dividiram em relação à adesão (Brasil, EUA, Holanda, Rússia etc.) e aqueles que não aderiram (Japão, Suécia e Bielorrússia).

Além de formação discursiva, cena discursiva e intriga, trabalharemos com mais um par conceitual nesse estudo: 'atos enunciativos' e 'forma discursiva'. Esta última sendo a economia dos atos enunciativos no discurso jornalístico. Vamos especificar mais essas hipóteses conceituais e sua aplicação no estudo a seguir a partir do próprio material trazido por O Globo. Antes, partiremos para a descrição do material coletado, já com seus vestígios discursivos e indícios históricos atravessando a linguagem jornalística.

Em relação ao tratamento do corpus, foram analisadas as ocorrências da locução nominal 'isolamento social' nas duas primeiras semanas a partir do dia seguinte ao anúncio das medidas pelos governadores. Utilizamos a técnica de recortes a partir de cotextos, destacando o segmento textual (ST) em que a locução ocorre. Pelo espaço exíguo deste texto, não nos seria possível trazer todas as ocorrências efetivamente analisadas, mas aqui há exemplos de todas as matérias veiculadas pelo jornal no período de 16 a 26 de março, quando o veículo se reposiciona discursivamente de modo significativo.

\section{RESULTADOS, ANÁLISE E DISCUSSÃO}

Realizada no próprio jornal em sua versão digital, a busca pelo termo 'isolamento social', concernente à pandemia de Covid-19, retornou 156 ocorrências para todo o mês de março. Nesse texto, trouxemos dados do dia 16, primeiro dia após o anúncio das medidas de isolamento por governadores, até o dia 26, quando o jornal entra em embate direto com o Governo federal, retornando 72 ocorrências. A locução apareceu pela primeira vez nesse mesmo mês, justamente às vésperas da adoção da medida por alguns governadores e prefeitos. No ano, ele já aparece vinculado à pandemia, o que caracteriza um reposicionamento semântico sem transição de sentido. Como exemplo comparativo, no ano anterior, que registrou cinco ocorrências, a expressão apareceu em matérias sobre idosos e crianças, mas sempre como 'algo a ser evitado'.

Ela aparece, por exemplo, numa reportagem de 2019 (DOS..., 2019, p. 19), que tratava do número de idosos com mais de 80 anos no Brasil. O segmento em que aparece a expressão acentua o valor negativo de 'isolamento social' em uma relação 'causal' com a depressão:

ST1 - Além de atividades que estimulam a parte cognitiva, (o centro-dia) evita o isolamento social, que gera depressão (DOS..., 2019, p. 19).

iv A Covid-19 acabou por representar, do ponto de vista teórico, aquilo que na Análise de Discurso denominamos o Real da História; aquilo que não está concebido, significado, que escapa aos discursos constituídos, mas que existe para além da memória. Ao irromper, com sua assustadora imprevisibilidade, essa pandemia tem o poder de afetar discursividades "de aparência logicamente estável” (PÊCHEUX, 2002, p. 28). O conceito de Real veio da psicanálise lacaniana e, desde então, vem sendo objeto de ampla discussão filosófica. A título de exemplo, para discussão sobre o conceito de Real em filosofia, numa leitura entre a psicanálise e o marxismo, consultar Zizek (2003), que parte do acontecimento 11 de Setembro, para mostrar como esse "Real" não é domesticável simbolicamente. Em psicanálise, recomenda-se o próprio Lacan (1974-1975). Para o Real em Análise de Discurso, uma revisão importante é empreendida por Paveau (2008). 
Num outro exemplo, uma reportagem sobre segurança de brinquedos (título: Atenção aos riscos na escolha de brinquedos), o jornal ouve um especialista sobre a adequação de objetos lúdicos para cada etapa da infância. Novamente, o termo 'isolamento social' aparece com valor negativo, como um mal em si mesmo.

ST2 - Até dois anos, as crianças não devem ter contato com telas, isso atrasa o desenvolvimento motor, ‘causa isolamento social' (ATENÇÃO..., 2019, p. 38).

No ano de 2020, o termo aparece em março já no sentido de medida de prevenção ao contágio e, de certa forma, sustenta um valor também defensável, embora não poucas vezes os efeitos negativos do isolamento social para a saúde física e mental tenham sido ressaltados. Do ponto de vista da extensão semântica, praticamente todas as referências se davam em relação às medidas de prevençãov . Não houve outra ocorrência no período analisado.

É nesse momento que o jornal se põe em cena e passa a disputar espaço como sujeito do discurso autorizado tendo como fundo o cenário pandêmico. Desenvolver-se-á, a partir de então, uma maior incidência de atos enunciativos de injunção e persuasão, mais que expositivo e narrativo; o que mudará de certa maneira a forma discursiva das notícias e reportagens do jornal. E aqui apresentamos, antes de passar aos enunciados propriamente ditos, algumas observações sobre o que viemos denominando cenários discursivos.

As discussões sobre medidas de mitigação contra a pandemia já vinham sendo discutidas desde que o vírus foi detectado em Wuhan, China, e mostrou sua forte tendência a se espalhar. Surpreendeu-nos que nem 'isolamento social' nem 'distanciamento social' - locução que buscamos somente num momento prévio da análise para efeito de contextualização - tenham aparecido desde o início da epidemia naquele país, ou mesmo na sua chegada a países europeus.

No Brasil, o primeiro caso foi oficialmente registrado em 26 de fevereiro, mas só em março também apareceria a expressão 'distanciamento social'vi. Ao longo do mês e até o final do primeiro semestre, as duas expressões conviveram, mas foi muito mais frequente o conceito de 'isolamento'. A memória das duas locuções, no entanto, aponta para sentidos distintos.

Por exemplo, no ano anterior, 'distanciamento social' aparece apenas uma vez no arquivo do jornal, remetendo ao sentido de intolerância em relação ao outro:

ST3 - No aspecto político, está cada vez mais difícil aproximar as pessoas para encontrar uma saída conjunta para o distanciamento social (ERROS..., 2019, p. 3).

Em nenhum dos dois casos, de 'distanciamento' e de 'isolamento social', portanto, temos uma memória discursiva que contemple os valores positivos que tomaram a partir de março. Parece-nos, portanto, que houve uma importação semântica - de outros países - que acabaria por ressignificar estas duas 'expressões'. De certa forma, podemos dizer que testemunhamos nesse caso um pequeno acontecimento discursivo, uma ruptura diante de um percurso de sentidos estabelecido e estabilizado em língua portuguesa.

Em 14 de março, 'distanciamento social' aparece em sentido totalmente outro: uma medida de prevenção necessária, atravessada pelos discursivos de prevenção e risco, ou seja, outra relação interdiscursiva,

\footnotetext{
v Do ponto de vista discursivo, extensão semântica, ou o alargamento de sentidos dados a uma palavra, é um dos efeitos dos processos metafóricos. Esse processo leva a deslocamento ou mesmo ruptura com sentidos anteriores regularizados em processos de paráfrase (ORLANDI, 2009).

vi Conceitualmente, o isolamento social seria a reclusão domiciliar voluntária, ou confinamento; e o distanciamento, as medidas de afastamento entre pessoas, mesmo que estejam num mesmo espaço, no caso de não ser possível o isolamento.
} 
marcando um deslocamento do ‘denunciável’ para o ‘desejável’. Movimento análogo aconteceria dois dias depois com 'isolamento social': mas em outra direção - passaria de efeito de risco (risco de isolamento social) para prevenção de risco (sem o isolamento social, há risco).

Se as duas expressões acabam por ser intercambiáveis no cenário da pandemia, esse fenômeno semântico não era plausível anteriormente, quando 'isolamento social' estava quase sempre ligado a sofrimento mental e solidão e 'distanciamento social' a obstáculo à convivência. Uma expressão tem história na memória dos discursos sobre saúde; outra não.

Portanto, o que vai fazer a aproximação entre as duas expressões não é tanto uma memória do dizer, mas o cenário do dizer, porque de certa forma mudam os elementos constitutivos de fronteira discursiva. Há um rearranjo, uma reconfiguração dos elementos em jogo, graças a um acontecimento histórico e certa resposta discursiva. A língua, atravessada pela história, agora vê aproximação de sentidos onde não via.

\section{Isolamento social: injunção e discurso pedagógico}

Essa nova espacialização dos sentidos, esse novo jogo de fronteiras semânticas, vai ficar cada vez mais evidente no decorrer do mês, o que nos obrigará a fazer um acompanhamento cronológico individual de cada expressão até seu ponto de saturaçãovii, o que parece ocorrer no Globo no dia 26 de março, quando "isolamento social" (GOVERNADORES..., 2020, p. 1) passa a constituir um campo semântico de disputas.

Mais especificamente, é no dia 26 de março que O Globo passa a se posicionar numa relação de oposição explícita à tese do presidente da República, Jair Bolsonaro, de que o melhor seria o afrouxamento das medidas restritivas em nome da economia, a partir da adoção do "isolamento vertical" (GOVERNADORES..., 2020, p. 1). É quando o jornal 'muda de cena' e passa a fazer parte da intriga discursiva política. Dias depois, o presidente passaria a desafiar as recomendações de distanciamento social, com estímulos a aglomerações. Neste trabalho, no entanto, vamos nos deter no embate sobre o isolamento social.

Vejamos então uma série de segmentos textuais, contendo a expressão 'isolamento social', que consideraremos daqui em diante nosso ponto de ancoragem para a análise ${ }^{\text {viii. }}$

ST4 - Fórmula do Brasil contra vírus falhou na Europa. Países que evitaram crescimento exponencial ou frearam epidemia estão todos na Ásia e implementaram testagem maciça de casos e 'medidas draconianas de isolamento social' e restrição de circulação (JOGO..., 2020, p. 6, destaque nosso).

Essa é o segmento textual inaugural em que aparece o termo 'isolamento social' pela primeira vez ligado ao acontecimento histórico da pandemia ${ }^{\text {ix }}$.

vii Ponto de saturação ou ponto de estofo é o momento em que as regularidades se apresentam como constituídas diante do processo de análise e já não apresentam mais tanta variação relevante. Em nosso caso, como ignoramos os meses subsequentes a março, não podemos afirmar qualquer imobilidade de sentidos a partir do período não analisado. Portanto, nosso 'ponto de saturação’ será referente a março especificamente.

viii Durante o mês de março, foram contabilizadas dez matérias antes do dia 26 e 34 notícias e reportagens a partir de então. Chamamos 'ponto de ancoragem' o que em outras abordagens se denomina de 'descritor'. Mas acreditamos ser mais apropriado adotar o primeiro termo porque remete a 'ponto de ancoragem de sentidos', significantes irradiadores, que de certa forma organizam e submetem uma textualidade qualquer. Do ponto de vista metodológico, os pontos de ancoragem - que podem ser uma palavra, uma expressão, um traço de imagem etc. - servem como lócus privilegiado de observação de processos discursivos em meio a um texto ou textualidade.

ix Em outros idiomas, temos esses outros termos: em italiano, era ressaltado o 'stato d'emergenza', que previa entre outras medidas a 'quarentena', morfologicamente idêntica ao português; em espanhol, predominou 'cuarentena'; em inglês, prevaleceu 'social distancing' e 'quarantine', não havendo transição semântica da locução 'social isolation', que permaneceu com o sentido de 'estado de risco para doença e sofrimento'; em francês, o termo usado foi 'quarantaine'; e em alemão, recorreu-se amplamente às locuções inglesas Corona-Lockdowns, com a recomendação de permanência em casa, a ‘Quarantäine'. Em algum momento, em todos esses idiomas, manteve-se algo similar a 'distanciamento social' ('social distancing', em inglês; 'distanza soziale', em italiano; 'distanciation sociale', em francês; 'distanciamento', em espanhol, e 'physischer Distanz', em alemão). Foram os falantes de língua portuguesa que trouxeram ênfase no termo 'isolamento', num diálogo incomum com uma não memória do sentido dominante dessa palavra. 
A locução exata ('isolamento social') aparece então em um segmento textual em que são enfatizadas as medidas draconianas (impositivas e autoritárias). O termo marca sua estreia em O Globo, portanto, associado a imposição e inflexibilidade contra o fracasso. Daí para frente, confinamento, quarentena, medidas de mitigação e distanciamento social se tornaram comuns ao longo das coberturas. $\mathrm{O}$ termo mais frequente, no entanto, fora 'isolamento'. Em março, mês em estudo, foram 720 ocorrências desse lexema, contra 702 de 'quarentena', que acabou se tornando mais popular no dia a dia. O registro jornalístico, no entanto, deu preferência a 'isolamento' e 'isolamento social' quando se tratava de política pública e recomendação de autoridades sanitárias.

No dia seguinte, o jornal abriria um boxe explicativo, com verbetes apontando para as diferenças entre isolamento e distanciamento social. É claramente um ato enunciativo de caráter injuntivo (instrução, prescrição, explicação de procedimentos etc.), ao contrário da primeira matéria do dia anterior, em que o caráter dominante é persuasivox ${ }^{x}$

ST5 - Isolamento social. Se o diagnóstico for confirmado, deve ficar em casa em isolamento. Se o diagnóstico for negativo, deve manter-se em casa o máximo de tempo possível para não correr o risco de se infectar (ISOLAMENTO..., 2020, p. 11).

ST6 - Distanciamento social. O indicado é sempre evitar aglomerações. Quando for preciso sair de casa, tentem manter pelo menos 1,5 m de distância das demais pessoas para evitar infecção (ISOLAMENTO..., 2020, p. 11).

Rippel, Campos e Alves (2016) vêm trabalhando há algum tempo com a hipótese de que a classificação genérica da notícia e da reportagem como textos informativos é insuficiente do ponto de vista da compreensão de suas variáveis e complexidade. Adotaram, assim, em outras publicações a análise de atos enunciativos entre os quais o narrativo, o persuasivo, o expositivo, o injuntivo e o lúdico - os quais, a cada caso, de modo heterogêneo e não exclusivo, constituiriam uma forma discursiva, a própria economia dos atos.

Na reportagem acima (ISOLAMENTO..., 2020, p. 11), em que O Globo reserva um boxe para instruir o leitor (e, por extensão, a população) quanto ao que deve ser feito durante a crise sanitária, temos um jornal, enquanto sujeito do discurso, incorporando um discurso pedagógico e projetando sobre o leitor a imagem de ‘sujeito a ser instruído’. Trata-se de projeção imaginária, que até estabelece o modo como se formula a textualidade, mas que não garante absolutamente a identificação do leitor nessa posição ${ }^{\mathrm{xi}}$.

Identificando-se à autoprojeção imaginária como sujeito do discurso pedagógico, o jornal lança a campanha \#tamojunto, que mobiliza artistas para o convencimento da população a ficar em casa. A forma discursiva da notícia e da reportagem varia de texto a texto: ora temos a predominância da injunção, que é mais constante; ora fica bem marcada a enunciação persuasiva. Os segmentos abaixo mostram esse lugar ocupado pelo jornal em matérias que assumem uma característica de 'serviço’xii.

ST7 - \#tamojunto. Artistas fazem campanha para convencer sobre a importância do isolamento social na epidemia de coronavírus, e transmitem na rede shows, peças e cursos - além de palavras de solidariedade. (\#TAMOJUNTO..., 2020, capa do Segundo Caderno)

x Sobre atos discursivos no jornalismo (narrativo, persuasivo, expositivo, injuntivo e lúdico), ver Rippel, Campos e Alves (2016).

xi Projeção imaginária, no singular ou no plural, foi um dos primeiros conceitos a aparecer na Análise de Discurso, pelas mãos de Pêcheux, seu fundador, ainda na primeira fase, a de 1969. O conceito define o pressuposto de que "todo processo discursivo supõe, por parte do emissor, uma antecipação das representações do receptor (PÊCHEUX, 2010, p 83). Nesse mesmo texto inaugural, Pêcheux mostra que as projeções se dão de forma cruzada entre aquele que fala e aquele com quem se fala e, também, a partir da constituição de imagens de si (PÊCHEUX, 2010).

xii Sobre jornalismo de serviço, ver Sobrinho (SOBRINHO, 2014). 
ST8 - A rede também está fechando parcerias com empresas de delivery para atender aos clientes neste período de isolamento social. (LOJISTAS..., 2020, p. 28)

ST9 - Em tempos de isolamento social, bares e restaurantes se preparam para aumento do número de pedidos de entregas em casa, seja adotando serviço próprio (além dos aplicativos), seja criando ofertas e deixando de cobrar taxa de delivery. (CONTRA..., 2020b, capa do caderno Rio Show) ${ }^{\text {xiii }}$

O ato narrativo é mais enfático ao apontar problemas causados pela crise sanitária ou pela não adesão de parte da população. Até então, o jornal não chegaria a produzir 'denúncias' de condutas desaconselhadas pela vigilância sanitária, mas, antes, alertas de não cumprimento, ou relato de dificuldades vividas por conta do isolamento. Como nos casos abaixo:

ST10 - Já o síndico profissional Lucas Tostes, da LT gestão, afirma que, apesar de todos os avisos nos elevadores e aplicativo de moradores, alguns insistem em não cumprir o isolamento social. (CORONAVIRUS..., 2020, capa do caderno Morar Bem)

\begin{abstract}
ST11 - Os consumidores sumiram, as contas, não. Com este cenário, as fintechs (startups financeiras) registraram um aumento significativo de pedidos de empréstimo na última semana, quando o governo estadual determinou o isolamento social. (HORA..., 2020, capa do caderno Boa Chance)

ST12 - Por conta do perigo, parentes de quem está nos grupos de risco têm se distanciado, levando quem já enfrenta a vulnerabilidade causada pela idade ou pela doença ao isolamento social justamente em um período de tantas incertezas. Dona Carmem comemora um século de vida com os funcionários de uma casa de repouso em Belo Horizonte. (AFASTAMENTO..., 2020, p. 12).
\end{abstract}

\title{
O dia seguinte: $\mathrm{O}$ Globo entra na cena política
}

O pronunciamento do presidente da República na noite do dia 24 de março, em cadeia nacional de rádio e televisão, e reproduzido na manhã do dia 25, via internet, levou O Globo a mudar de cena e passar ao embate político. Nesse momento, podemos dizer que o veículo começa a fazer parte de uma intriga, como sujeito do discurso, identificado a uma formação discursiva determinada, aquela própria ocupada pelas autoridades sanitárias e cientistas a favor do isolamento. Daí para frente, até o final do mês, seguiu-se mais que o triplo de matérias veiculadas até a véspera, dia 25, com o termo 'isolamento social'.

Em síntese, temos uma mudança, ao menos parcial, na tonalidade 'de campanha de conscientização social', para 'embate político'. Tratava-se, a partir daí, não somente de orientar e instruir, como também mais acentuadamente de persuadir o leitor. O jornal não abandona o discurso pedagógico, mas alia a este um discurso de embate, com predominância de atos persuasivos, dando nova tonalidade à forma discursiva das notícias e reportagens a partir de então.

Porém, que leitor é projetado quando se tem um quadro de intriga discursiva em cuja cena o próprio jornal atua? Se temos $o$ sujeito-leitor a ser instruído por um lado - quando o jornal, como sujeito do discurso, passa a se posicionar em meio a uma intriga política - o que se projeta sobre o leitor é a imagem de aliado ou adversário (a ser demovido). São comuns as análises que atribuem aos textos de opinião dos veículos a função persuasiva. Em geral, isso se deve a uma certa rigidez das tipologias de gênero. Veremos abaixo como o jornal faz da notícia e da reportagem um lugar de luta e polêmica:

xiii No dia 25, O Globo voltaria à campanha da seguinte forma: "(ST13) 'A premissa é a mesma? Transmitir ao vivo - pelo Instagram dos artistas, no site e nas redes sociais do GLOBO - pocket-shows caseiros de grandes nomes da MPB para ajudar a conscientizar o público sobre a importância do isolamento social no combate ao avanço do novo coronavírus, e também para mostrar que, mesmo estando separados, todos podem estar unidos"' (CONTRA..., 2020b, capa do caderno Rio Show). 
ST14 - O presidente da Câmara fez duras críticas ao posicionamento de Bolsonaro. Maia afirmou que eles não devem se desviar do debate sobre o isolamento social e sugeriu que a mudança da posição do presidente se deve a investidores que atuam na Bolsa de Valores, que teve fortes perdas nas últimas semanas. (REAÇÃO..., 2020, p. 10).

Exploremos mais esse segmento, mostrando a cotextualidade em que ela se apresenta ${ }^{\mathrm{xiv}}$. Observe-se a mancha gráfica dessa página do jornal.

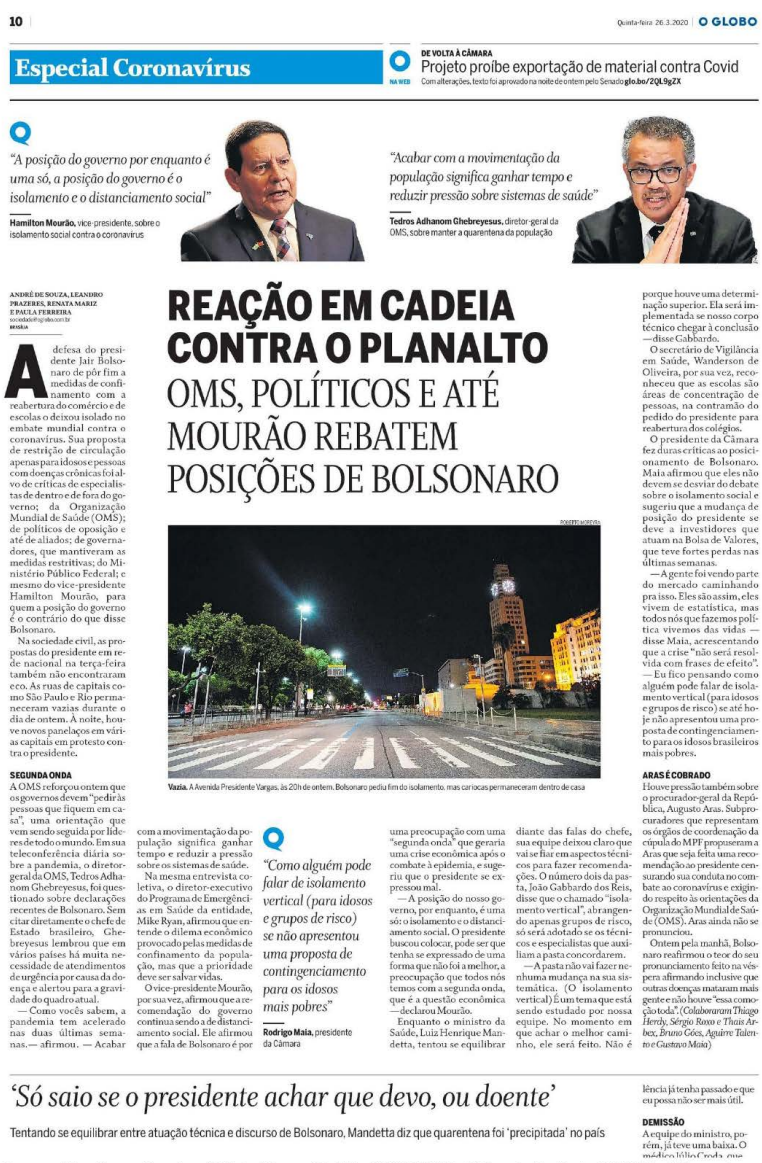

Figura 1 - Página do jornal O Globo, 26/03/2020, p. 10

Fonte: O Globo (REAÇÂO..., 2020).

As textualidades gráfico-visuais, nesse caso, a fotografia e a diagramação, são fundamentais para compreender o modo como o jornal formula seu lugar de embate (MOUILLAUD, 2012a; 2012b). No alto da página à esquerda aparece a imagem do vice-presidente, Hamilton Mourão, mas o personagem principal da notícia é a do presidente da República, Jair Bolsonaro, cuja imagem está ausente da página. O vice aparece para contestar a fala do titular da cadeira, ao lado do diretor geral da Organização Mundial da Saúde, Tedros Ghebreyesus - ambas em janelas superiores, marcando destaque de declaração.

Assim, o jornal se ancora em duas autoridades, uma política e uma sanitária (internacional), desautorizando a própria figura do presidente. No centro da página, temos a fotografia de um centro urbano vazio, mostrando a adesão da população ao isolamento. A população é significada pela sua ausência. Acima da foto, temos o título: Reação em cadeia contra o Planalto: OMS, Políticos e até Mourão rebatem posições de Bolsonaro (2020, p. 10). Estamos aqui no nível da formulação discursiva, da textualização, em que

xiv Em análises linguístico-discursivas, contexto é o segmento amplo de texto em que o segmento específico analisado se encontra. Mas quando se diz segmento amplo, pode-se referir tanto a um período, a um ou mais parágrafos, quanto a uma página inteira, ou, em alguns casos um conjunto de páginas. Tudo depende do critério e objetivo do analista. Como, nesse caso específico, excepcionalmente, consideramos elementos gráficos e visuais, optamos por textualidade, referindo-nos, então, à cotextualidade. 
aparecem as marcas linguísticas e semiológicas da filiação do sujeito, deste sujeito institucional que se filia a um discurso institucional sanitário.

ST14 ressalta a oposição do presidente da Câmara dos Deputados, que também é o chefe do Legislativo Federal. Mais do que um relato dos acontecimentos políticos, temos uma forma discursiva fortemente persuasiva da notícia, quando consideramos a cotextualidade ampla em que ele, o relato, está inserido. É outro lugar projetado pelo jornal para o próprio veículo, que não 'narra' os acontecimentos a partir da posição de observador, mas se insere na própria intriga, como ator e personagem da disputa de sentidos. A edição vai confirmando passo a passo essa virada de papéis.

Estamos diante de um acontecimento discursivo marcado por uma crise, a crise sanitária. O veículo se posiciona tradicionalmente como sujeito do discurso neoliberal, ou economicista (DUGNANI, 2015). O mercado de ações quase nunca aparece como ator opositivo às suas falas. Em ST14, temos o presidente do Congresso anunciando que a posição do presidente com relação às medidas emergenciais é fruto de demandas de acionistas da Bolsa de Valores, representando agentes econômicos. Pode se tratar de um acontecimento limitado ao cenário discursivo da pandemia conforme ele se constitui no Brasil, mas ainda assim mostra algum ponto de ruptura no discurso ocupado pelo jornal, ainda que de forma provisória, revertendo regularidades até então observadas.

No mesmo dia, uma série de notícias e reportagens viriam reafirmar essa imagem na qual o jornal se reconhece. Por exemplo, sem citar a locução nominal 'isolamento social', que aparece apenas em um informe publicitário ao lado, o Globo traz o exemplo da Itália, que ignorou as medidas restritivas, com grande título: Contra o caos, o erro italiano. Quando tinha 17 mortos, governo menosprezou vírus (CONTRA..., 2020a, p. 11).

Vemos aqui uma reportagem de caráter anafórico, em que o objeto de discurso não aparece explicitamente, mas lhe faz remissão retroativa ${ }^{\mathrm{xv}}$. O objeto de discurso é a fala de Bolsonaro, apregoando o "isolamento vertical”, ou seja, a quarentena somente para idosos e outros grupos de risco. No boxe ao lado, o título é "Isolar idosos não basta". O Globo traz para a cena de embate atores da política, do empresariado e da ciência para sua empreitada. Há marcadores linguísticos que mostram que o discurso não é tanto mais o de orientação - injuntivo - mas de persuasão, deixando as matérias de caráter mais injuntivo para os cadernos especiais. Observem os textos grafados nas STs abaixo:

ST15 - 'Apesar da sinalização’ de que pretende relaxar algumas medidas da quarentena imposta na cidade, o prefeito Marcelo Crivella 'garantiu' que o 'isolamento social' é a posicão de consenso definida em uma reunião com o gabinete de crise e a comunidade científica ontem de manhã, no Riocentro.(CONFLITO..., 2020, p.13)

ST16 - Cadeia interrompida. 'Por que é importante' atuar cedo no isolamento social para frear a Covid-19. (ISOLAR..., 2020, p. 14)

ST17 - O trabalho mostra que o vírus Sars-Cov-2 já se propagou no país a ponto de apresentar características que o distinguem dos coronavírus introduzidos. 'Éa comprovação genética da transmissão comunitária, e veio acompanhada de um apelo dos pesquisadores sobre a necessidade do isolamento social para conter' o avanço da 'pandemia' no país (TRANSMISSÃO..., 2020, p. 15)

Nos segmentos acima, teremos o discurso de reafirmação diante de um enunciado outro, o da negação ao isolamento total. Em ST15, o prefeito da cidade do Rio de Janeiro é visto pelo jornal nesse momento como um aliado de primeira hora do presidente da República, mas "apesar da sinalização" (CONFLITO..., 2020,

xv Tomamos aqui, portanto, anáfora dentro de uma proposta discursiva. Numa perspectiva linguística, 'anáfora' é o processo textual de remissão retroativa a um referente, necessária para a progressão textual. No nosso caso, trabalhamos com 'objeto de discurso', e não com a noção de referente; além de conceber uma percepção estendida de textualidade. Sobre anáfora, em linguística, ou mais precisamente em Linguística Textual, ver Marcuschi (2005). 
p. 13) em seguir o pedido de afrouxamento defendido pelo presidente, Crivella garantiria a continuidade da política de estímulo ao isolamento social (CONFLITO..., 2020, p. 13). Sem citar 'isolamento vertical', defendido pelo adversário de contenda do jornal, em ST16 (ISOLAR..., 2020, p. 14), o jornal reafirma a importância do isolamento social para interromper a cadeia de contágio. Para isso, na mesma edição, em ST17 (TRANSMISSÃO..., 2020, p. 15), o veículo recorre à autoridade da ciência.

Essas reportagens se encontram, como significantes, numa cadeia sintagmática, não de palavras somente, mas numa dimensão mais ampla de textos encadeados, imagens fotográficas e ilustrativas, diagramação, articulação de vozes políticas, científicas, produzindo uma macrotextualidade, que nos serve de base de observação dos fenômenos discursivos.

Paralelamente, na página 17, uma reportagem sobre habitações com adensamento de moradores sublinhava a precariedade como um empecilho para o distanciamento social e o isolamento. Da mesma forma, na página 26, o jornal trazia a declaração de um diretor da Sindilojas de São Paulo de que já havia 145 mil estabelecimentos fechados por causa do isolamento social, mas que a reabertura "deveria ser bem planejada" (GOVERNADORES..., 2020, p. 1).

Como dito acima, o Globo não abandona totalmente o discurso pedagógico, mas este se torna mais presente nos cadernos especiais, como o de Cultura (Segundo Caderno), de turismo (Boa Viagem) e o de Gastronomia, muitas vezes diluído em dicas, sugestões e exemplos, como nas passagens grifadas abaixo:

ST18 - Acostumada a se apresentar para plateias cheias de brasileiros, lá e aqui, Carminho aceitou participar do festival on-line '\#tamojunto, para amenizar o isolamento social causado pela pandemia’. (SEGUNDO..., 2020, capa do Segundo Caderno, junto às letras garrafais que abrem a entrevista: "A economia não pode vir antes das pessoas")

ST19 - Cozinhar em família, uma receita de sucesso. 'Chefs indicam pratos doces e salgados fáceis para preparar com os filhos em dias de isolamento social' (COZINHAR..., 2020, capa do caderno Gastronomia)

ST20 - Graças a sites que transmitem em tempo real (ou quase) as imagens captadas por câmeras espalhadas por todos os continentes, 'é possível dar uma volta ao mundo sem cruzar as fronteiras do isolamento social' (JANELA..., 2020, capa do caderno Boa Viagem)

\footnotetext{
ST21 - Para driblar o isolamento social provocado pela pandemia do coronavírus, produções teatrais passaram a colocar, a disposição do público, 'vídeos de seus espetáculos na íntegra em plataformas gratuitas na internet'. (CORTINA..., 2020, capa do Rio Show no sofá, que é uma seção de agenda de espetáculos no Segundo Caderno)

ST22 - Em um dos episódios do clássico "Tudo o que você sempre quis saber sobre sexo (mas tinha medo de perguntar)", de Woody Allen, os espermatozoides são paraquedistas. O próprio Allen interpreta um deles, com personalidade particular: tem medo do desconhecido. Imagine a mesma cena hoje, quando uma pandemia leva bilhões de pessoas ao isolamento social. 'Quem não está com medo de saltar no desconhecido?' (MUITO, 2020..., p. 8, Segundo Caderno)
}

O ST22, último a ser apreciado nesse estudo, aparece numa reportagem sobre sexo em tempos de isolamento ("Muito vibrador e pouco poliamor: o sexo na quarentena"). Acima, a jornalista Cora Ronai, em sua coluna, escreve um texto cujo título é "Sou velha sim, e daí?” (MUITO..., 2020, p. 8). Na véspera, todo um debate se construiria em outros meios sobre um suposto desapreço do governo pela vida dos idosos em privilégio da economia.

Depois, a partir do dia 27 e até o final do mês, se seguiram mais 24 textos, com 84 ocorrências da locução nominal em estudo, entre reportagens e artigos com ênfase acentuada no isolamento, mas que não chegaram a representar uma nova ordem discursiva, sempre com alusão direta ou indireta às iniciativas do 
presidente, inclusive de demonstrações públicas de quebra do isolamento. Tínhamos chegado, então, no próprio dia 26, ao ponto de saturação da análise para o mês de março.

\section{CONSIDERAÇÕES FINAIS}

Uma análise discursiva de textos de O Globo em relação às suas projeções imaginárias, cena e intriga discursivas, atos e formas discursivas, mostra-nos que o jornal teve dois momentos durante os primeiros onze dias de cobertura sobre as medidas de mitigação, com distanciamento e isolamento social, preconizadas pela Organização Mundial da Saúde, cientistas e autoridades sanitárias do país.

Num primeiro momento, o jornal assume posição num discurso pedagógico, com ênfase na forma discursiva predominantemente injuntiva, embora não exclusiva. A intervenção do presidente Jair Bolsonaro levou o jornal a efetuar certo deslocamento na direção de um discurso de embate, com predominância persuasiva, deslocando também a imagem de um leitor a ser instruído para um leitor a ser convencido contra a posição presidencial.

Diremos que, nesse momento, o veículo, enquanto sujeito do discurso, põe-se na cena política e participa efetivamente da intriga discursiva. Identificamos aqui algo que pode ser considerado um efeito da crise, esse acontecimento histórico-sanitário, com repercussões discursivas: um jornal predominantemente de filiação neoliberal move-se numa posição relativamente crítica à prioridade da economia sobre a saúde e a vida.

Internacionalmente, essa discussão já estava posta: na campanha 'Milão não para' (de efeitos catastróficos), nas minimizações do presidente americano sobre a gravidade da pandemia e em países que demoraram ou não quiseram aderir às recomendações de autoridades sanitárias. Mas a discussão 'vida versus economia', a julgar pelo arquivo construído no processo de análise, não aparece tão claramente no primeiro momento do jornal. A partir do 'dia seguinte', essa clivagem de posições discursivas é posta, e o debate público se acirra. O Globo, então, se filia aos posicionamentos críticos à ordem de primazia do econômico na sociedade.

Uma questão precisa ser lembrada para finalizar: toda escolha analítica deixa de fora uma série de aspectos a serem analisados. Partimos de um ponto de ancoragem textual: o descritor 'isolamento social', mas é possível que, com a escolha de outros, poderia haver resultados suavemente diferenciados. Diremos 'suavemente' porque nos apresentaria variáveis não contempladas aqui, mas que, de certa forma, não poderiam apontar para uma tendência radicalmente distinta do que identificamos.

É certo que a ênfase sobre o noticiário deixa de fora os textos de opinião e análise. No entanto, analistas de imprensa sabem da mesma forma que, embora vozes contrárias ao seu posicionamento possam ser contempladas, os veículos tendem a alinhar o editorial e parte dos articulistas contemplados às suas posições vistas no noticiário.

Uma terceira dificuldade é o recorte temporal. Discurso é movimento, e os dias seguintes da cobertura poderiam trazer outros elementos. Porém, de novo, lançando mão da analogia com a fotografia, o registro de um movimento termina no instante fotografado, mas não se esgota nele. A partir dele, podem-se fazer projeções cinéticas, baseadas não somente na materialidade em questão, mas também em nossa experiência de vida.

Importa, no entanto, saber que, em certo momento da história, dentro do recorte escolhido, o que temos foi esse movimento discursivo. Outras análises darão conta dos capítulos seguintes.

\section{REFERÊNCIAS}

\#TAMOJUNTO. O Globo, Rio de Janeiro, 17 mar. 2020. Segundo Caderno, capa.

AFASTAMENTO em dose dupla. O Globo, Rio de Janeiro, 24 mar. 2020. p. 12. 
ATENÇÃO aos riscos na escolha de brinquedos. O Globo, Rio de Janeiro, 06 out. 2019. p. 38.

CENTRAL FOR DISEASE CONTROL AND PREVENTION (CDC). 2014-2016 Ebola Outbreak in West Africa, [s. I.]: CDC, 8 mar. 2019. Disponível em: https://www.cdc.gov/vhf/ebola/history/2014-2016-outbreak/index.html. Acesso em: 30 jul. 2020.

CONFLITO no Rio. O Globo, Rio de Janeiro, 26 mar. 2020. p. 13.

CONTRA o caos, o erro italiano. O Globo, Rio de Janeiro, 26 mar. 2020a. p. 11.

CONTRA os médicos Trump quer reabrir EUA até a Páscoa. O Globo, Rio de Janeiro, 25 mar. 2020b. Rio Show, capa.

CORONAVÍRUS alerta geral. O Globo, Rio de Janeiro, 22 mar. 2020. Morar Bem, capa.

CORTINA fechada, palco visível: teatro migra para a internet. O Globo, Rio de Janeiro, 26 mar. 2020. Rio Show, capa.

COZINHAR em família, uma receita de sucesso. O Globo, Rio de Janeiro, 26 mar. 2020. Gastronomia, capa.

DUGNANI, Rodrigo. Análise dialógica do discurso neoliberal sobre a previdência brasileira nos jornais Folha de S.Paulo, O Estado de S. Paulo e O Globo. 2015. 280 f. Tese (Doutorado em Ciências Sociais) Pontifícia Universidade Católica de São Paulo, São Paulo, 2015.

DOS 80 anos em diante. O Globo, Rio de Janeiro, 26 mar. 2020. p. 19.

ERROS da esquerda. O Globo, Rio de Janeiro, 03 maio 2019. p. 3.

GOVERNADORES e cientistas rechaçam Bolsonaro, população fica em casa. O Globo, Rio de Janeiro, 26 mar. 2020. Capa, p. 1.

GUILHAUMOU, Jean-Jacques. Linguística e história: percursos analíticos de acontecimentos discursivos. São Carlos: Pedro \& João Editores, 2007.

HORA de refazer planos e pensar em alternativas. O Globo, Rio de Janeiro, 22 mar. 2020. Boa Chance, capa. ISOLAMENTO e distanciamento social: quando e como fazer. O Globo, Rio de Janeiro, 17 mar. 2020. p. 11.

ISOLAR idosos não basta. O Globo, Rio de Janeiro, 26 mar. 2020. p. 14.

JANELA aberta para o mundo. O Globo, Rio de Janeiro, 26 mar.2020. Boa viagem, capa.

JOGO dos sete erros: aglomerações em praias e manifestações mostram descaso. O Globo, Rio de Janeiro, 16 mar. 2020. p. 6.

LOJISTAS já negociam até moratória para aluguel. O Globo, Rio de Janeiro, 20 mar. 2020. p. 28.

MARCUSCHI, Luiz Antonio. Anáfora indireta: o barco textual e suas âncoras. In: $\mathrm{KOCH}$, Ingedore Villaça; MORATO, Edwiges Maria; BENTES, Anna Cristina (org.). Referenciação e discurso. São Paulo: Contexto, 2005. p. 53-101.

MARTIN, Yella Hewings. How do SARS and MERS compare with COVID-19? Medical News Today, Brighton: Healthline Media UK, 10 abr. 2020. Disponível em: https://www.medicalnewstoday.com/articles/how-do-sarsand-mers-compare-with-covid-19. Acesso em: 30 jul. 2020.

MOUILLAUD, Maurice. Da forma ao sentido. In: MOUILLAUD, Maurice; PORTO, Sérgio Dayrell (org.). 0 jornal: da forma ao sentido. Brasília: Ed. UnB, 2012a. p. 47-53.

MOUILLAUD, Maurice. A informação ou a parte da sombra. In: MOUILLAUD, Maurice; PORTO, Sérgio Dayrell (org.). O jornal: da forma ao sentido. Brasília: Ed. UnB, 2012b. p. 55-66.

MOULIN, Anne Marie. O corpo diante da medicina. In: CORBIN, Alain; COURTINE, Jean-Jacques;

VIGARELLO, Georges (org.). História do corpo: as mutações do olhar. O século XX. Petrópolis: Vozes, 2008. v. 3. p. $15-82$. 
MUITO vibrador e pouco poliamor: o sexo na quarentena. O Globo, Rio de Janeiro, 26 mar. 2020. p. 8.

ORLANDI, Eni Puccinelli (org.). Discurso e políticas públicas urbanas: a fabricação do consenso. Campinas: Editora RG, 2010.

ORLANDI, Eni Puccinelli. Análise de discurso: princípios \& procedimentos. 8. ed. Campinas: Pontes, 2009.

PAVEAU, Marie-Anne. O Redemoinho das palavras. Análise do discurso, consciente, real, alteridade. Matraga - Revista do Programa de Pós-Graduação em Letras da Uerj, Rio de Janeiro, v. 15, n. 2, dez. 2008. Disponível em: https://www.e-publicacoes.uerj.br/index.php/matraga/article/view/27905. Acesso em: 30 set. 2020.

PÊCHEUX, Michel. Análise automática do discurso (AAD-69). In: GADET, Françoise; HAK, Tony (org.). Por uma análise automática do discurso: uma introdução à obra de Michel Pêcheux. 4. ed. Campinas: Unicamp, 2010.

PÊCHEUX, Michel. Discurso: Estrutura ou acontecimento. Campinas: Pontes, 2002.

REAÇÃO em cadeia no Planalto. O Globo, Rio de Janeiro, 26 mar. 2020. p. 10.

RICOEUR, Paul. Tempo e narrativa. São Paulo: Martins Fontes, 2011.

RIPPEL, Nathália; CAMPOS, lara; ALVES, Wedencley. A Gazeta de Notícias e a Revolta dos Marinheiros: capítulo de uma história das práticas e formas discursivas na imprensa. In: ENCONTRO REGIONAL SUDESTE DE HISTÓRIA DA MÍDIA, 4., 29-30 ago. 2016. Anais [...]. Niterói: Alcar, 2016.

SACCHITIELLO, Bárbara. Circulação dos maiores jornais do país cresce em 2019. Meio \& mensagem, [s. I.], 21 jan. 2020. Disponível em: https://www.meioemensagem.com.br/home/midia/2020/01/21/circulacao-dosmaiores-jornais-do-pais-cresce-em-2019.html. Acesso em: 30 jul. 2020.

SEGUNDO em quarentena. O Globo, Rio de Janeiro, 26 mar. 2020. Segundo Caderno, capa.

SOBRINHO, Carlos Peres de Figueiredo. Jornalismo de serviço: política, discurso, representação e participação em disputa. 2012. 241 f. Tese (Doutorado em Sociologia) - Centro de Filosofia e Ciências Humanas, Universidade Federal de Pernambuco, Recife, 2014. Disponível em: https://repositorio.ufpe.br/ handle/123456789/11719. Acesso em: 30 jul. 2020.

TRANSMISSÃO comunitária. O Globo, Rio de Janeiro, 26 mar. 2020. p. 15.

WORLD HEALTH ORGANIZATION (WHO). Coronavirus disease 2019 (COVID-19) Situation Report - 46. [S. I.]: WHO, 2020. E-book. Disponivel em: https://www.who.int/docs/default-source/coronaviruse/situationreports/20200306-sitrep-46-covid-19.pdf?sfvrsn=96b04adf_4. Acesso em: 30 jul. 2020.

ZIZEK, Slavoj. Bem-vindo ao deserto do Real. Rio de Janeiro: Boitempo, 2003. 